\title{
IDEAS \& Changing the engines of change: Natural INNOVATIONS resource conservation in the era of social media
}

\author{
Mark Anderson-Wilk
}

ommunication has been used throughout human history to impart information, teach skills, influence attitudes and perceptions, moderate debate and disagreement, create connections between individuals and groups, inspire new ideas, and facilitate cultural and behavioral changes.

This article reviews the role communication has played in facilitating change in agricultural conservation in the past and suggests how new social media technologies could be used to advance conservation in the future.

\section{BRIEF HISTORY OF COMMUNICATION IN AGRICULTURE}

Until the mid-19th century, most agricultural information was communicated from farmer to farmer by word of mouth (Paskoff 1990). "[I]ncreased dissemination of knowledge through agricultural literature inclusive of monographs, published works of agricultural societies, and the growing number of periodicals finally culminated in what became known as the first Agricultural Revolution" (Fusonie 1975, quoted in Paskoff 1990, p. 332).

By the later half of the 19th century, daily newspapers such as the Chicago Tribune and Des Moines Register employed agricultural writers writing for farm audiences.

Boone et al. (2000) describe the rise of agricultural journals and magazines, beginning with American Farmer in 1819. By 1920, US farmers subscribed to between two and three farm periodicals on average. By 1970, farms in the United States were receiving an average of seven farm periodicals (Boone et al. 2000). Meanwhile, a comprehensive agricultural library collection in the United States grew from about 125 volumes in 1815 to over 2 million volumes by 1990 (Paskoff 1990).

Mark Anderson-Wilk is publishing leader in Extension and Experiment Station Communications, College of Agricultural Sciences, Oregon State University, Corvallis, Oregon.
Radio-especially weather and market reports-became an important communication tool for the agricultural sector in the 1920s. By the 1930s, radio was being used to deliver soil conservation information (Boone et al. 2000).

As the US population continued its shift in the 20th century from primarily agricultural to primarily nonagricultural, newspaper coverage of agriculture often changed focus from farm production and market issues to agriculture's impact on the environment and human health (Boone et al. 2000).

\section{COMMUNICATION AS ENGINE OF CHANGE}

Communication is often cited for its role in creating change (e.g., Rogers 2003; King 2003). Everett Rogers's classic 1962 "diffusion of innovations" communications theory described the process of new ideas or practices expanding into a social system through a sequence of adopters: innovators, early adopters, early majority, late majority, and laggards (Rogers 2003).

At the core of the conservation movement has been a communication movement. This is primarily because conservation requires change, and change requires communication.

During the course of its history, the conservation movement has been known by the general public in large part through popular books on conservation and environmental issues: Henry David Thoreau's Walden (1854), George Perkins Marsh's Man and Nature (1864), John Burroughs's WakeRobin (1871), John Muir's Our National Parks (1901), Gifford Pinchot's The Fight for Conservation (1910), William Vogt's Road to Survival (1948), Aldo Leopold's Sand County Almanac (1949), Rachel Carson's Silent Spring (1962), Barry Commoner's The Closing Circle (1971), Wendell Berry's The Unsettling of America: Culture and Agriculture (1977), Bill McKibben's The End of Nature (1989), Edward O. Wilson's The Future of Life (2002), etc.

These texts were sometimes controversial, sometimes insightful, but always provocative because they sought to cause change-that is, improvements in conservation policies and practices. Within the agricultural literature, Hugh Hammond Bennett's 1928 Soil Erosion: A National Menace is often cited for its catalyzing effect on the US soil conservation movement.

Communication has played a central role in soil conservation's grassroots efforts as well (Cressel 1994; Hoban 1992). Communication provides the "key process of bringing people together to cooperate towards addressing the problem of degradation of the environment and natural resources" (FAO 2006, p. 11). New social media (Web 2.0) tools now provide the conservation community the potential for greater reach and mobilization of conservation support.

Lamberti (2007) describes the agricultural communication efforts of Iowa's Beginning Farmer Center, which had an objective of shaping change in Iowa agriculture, including moving toward greater environmental sustainability. The center had limited success engaging audiences and thus creating change largely due to inadequate targeting of publications to the intended audiences. The importance of targeting audiences has been discussed for many years (e.g., Emery 1999). Tarrant et al. (1997) documented the ability to shape attitudes toward ecosystem management when audiences are well understood and targeted with appropriate messages.

Not only is audience targeting important,"different communications approaches may be needed at each stage of behavior change" (FAO 2006, p. 42). Rogers explains that people must go through awareness, interest, evaluation, and trial before they adopt or reject a new idea or practice (Rogers 2003). In addition, people often require exposure through multiple channels (Israel and Wilson 2006).

Mass media is effective at creating initial awareness and interest, but interpersonal communication is better at serving as a form of evaluation and trial (FAO 2006). New media technologies such as social networks can be used to efficiently 
facilitate rich, targeted interpersonal communications capable of creating exposure as well as mobilization on a large scale.

\section{POTENTIAL OF PARTICIPATORY}

\section{COMMUNICATION}

Effective communication is multidirectional (Rogers 2003). Communication is more likely to be effective-lead to increased knowledge, changed behavior, etc.-if people have an opportunity to ask questions, discuss with others, actively process content, and apply information in a social context (Brown and Adler 2008). When people feel like they are a part of the communication experience rather than just recipients of an informational product, they are more likely to be engaged with the material and use it (FAO 2006).

Until relatively recently, participatory communication was primarily limited to in-person or teleconferenced synchronous events. The ideal of participatory communication is now more readily realizable, without restriction to a particular time or location, with online social media tools. Social media provide the opportunity for people who were previously only on the receiving end of communications to become more actively engaged-to participate. This is sometimes referred to as "democratization" by those who are in favor of it and as "dumbing down" by those who don't like it.

In publishing, the old model usually consisted of one-directional, "push" communications used to transfer knowledge from experts to nonexperts. Audiences were typically recipients of published products and were on their own to understand and use the information that was provided. The new model offers interactive, participatory experiences. In the new model, audiences can ask questions, adapt the information to make it useful to themselves, learn from each other, and add value to the published material by contributing their perspectives and applications.

Participatory communication on the Web can include any of the following:

- Interaction between Users and System. Published content can be designed to provide users an interactive experience that does not actually involve other people. This can be achieved through user-guided navigation, quizzes, and games where users must actively think through issues related to the content.

- Interaction between Users and Experts. User-expert interactivity can be achieved through blogs and questionand-answer forums. Content specialists can become more effective at communicating information by listening to and being responsive to the users' questions and comments. The downside of ongoing expert-involved communications is that these efforts can be very time consuming.

\section{- Interaction between Users. When users} are allowed to read each other's comments, explain information to each other in terms they understand, and provide each other examples of how information applies to real-world situations, the users will typically experience greater engagement, improved retention of information, and greater likelihood of changed behavior or action as a result. The downside of user-to-user interaction is that information not supported by scientific evidence or vetted through peer review can be exchanged; however, a variety of moderation techniques can be used to minimize potential problems related to this.

\section{NEW MEDIA FOR CONSERVATION COMMUNICATION}

New communications technologies regularly emerge on the market. Specific media applications used today may be replaced by new technologies within a few years. Some examples of currently widely used digital media are discussed below.

Podcasting. Podcasting can be played on personal computers or mobile devices such as iPods (Xie and $\mathrm{Gu}$ 2007). An important feature of audio and video podcasting is that users can subscribe through RSS feeds and then listen to or watch the program on a variety of devices at a time that is convenient to them (Mocigemba 2008; Vogele and Garlick 2006).

The podosphere is still relatively young, filled with early adopters, but it is quickly growing (Mocigemba 2008). Vogele and Garlick (2006) used Google search results to provide an indication of the explosive proliferation of podcasting: in September 2004, a search for "podcasts" resulted in just 24 results, while the same search within a year later resulted in over 100 million results.

Mocigemba (2008) discusses how participatory podcasting can be used for grassroots sustainable development. Mocigemba believes podcasting can strengthen civil society, citizen deliberation, and political participation by encouraging debate and building community and civic engagement. Because of the low cost and flexible, distributed nature of podcasting, this technology is well suited to targeting audiences and giving a voice to a diversity of opinions (Mocigemba 2008). Podcasting can also be used to inform and mobilize groups.

Video. Moving pictures-movies, television, video-have long had a captivating effect on human beings, engaging them during the communication experience and motivating them afterward.

Communicating science through video in the past was often limited to high-production documentaries and educational programs because of the high costs of the equipment and the specialized skills needed for using it. Now, as digital video cameras have become less expensive and the Web becomes increasingly more video-centric, video is commonly used both by scientists to communicate their findings and by great numbers of people to communicate about ideas and issues of interest to them. Video is shared not only through popular sites such as YouTube and Vimeo, but also through academic- and scientific-focused sites such as Academic Earth and SciVee.

Blogs. Bruening (1991) found that farmers prefer to learn about environmental issues at local meetings and field demonstrations rather than through distributed communications products because of the ability for two-way communication at an event. While there is not an equal replacement for in-person communication, the two-directional communication offered through blogs does provide some benefits over one-directional publishing. Blogs can connect experts and audiences in an informal, open dialogue.

Like any medium, some blogs are well done and credible, and some are not. At 
least one study (Johnson and Kaye 2004) has found that blogs are viewed as highly credible by users on average, as credible or more credible than traditional sources.

Social Networks. Rogers (2003; Rogers and Kincaid 1981) identified the important role of communication networks in moving innovations into practice. People are social beings whose beliefs and actions are influenced by other people. With the recent advent of new social media, human networks are now more global, more efficient, and more targeted; that is, those people around the world who share a specific interest are now connecting with each other more quickly, more inexpensively, and with less reservation.

Many professional and scientific society publishers, including the Soil and Water Conservation Society (http://swcsnetwork.ning.com), are using social network technologies to enhance the networking capabilities and benefits of their members. Other niche social networks are sprouting up for nearly every target group (farmers, for example, can choose between a variety of networks such as Farmers for the Future and Farm On).

\section{CONCLUSION}

Podcasting, video, blogs, and social networks are just a few of the new media available in the conservation communication toolkit today. These technologies have the potential to help fulfill communication's role as an engine of change, and to do so more effectively than traditional communication efforts because of the social, participatory, and engaging nature of the new media.

\section{REFERENCES}

Boone, K., T. Meisenbach, and M. Tucker. 2000 Agricultural Communications: Changes and Challenges. Ames, IA: Iowa State University Press.

Brown, J.S., and R.P.Adler. 2008. Minds on fire: Open education, the long tail, and learning 2.0.Educause Review, January/February 2008:17-32.

Bruening, T.H. 1991. Communicating with farmers about environmental issues. Journal of Applied Communications 75(1):35-41.

Cressel, M.M. 1995. The three Ws of communicating conservation. Journal of Soil and Water Conservation 50(4):356-357.
Emery, M. 1999. Who's out there? Strengthening Internet communication for agriculture through consideration of audience dimensions and user needs. Journal of Applied Communications 83(1):27-41.

FAO (Food and Agriculture Organization). 2006 Information and Communication for Natural Resource Management in Agriculture:A Training Sourcebook. Rome: Food and Agriculture Organization, United Nations.

Fusonie,A.M.1975.Heritage ofAmericanAgriculture: A Bibliography of Pre-1860 Imprints. Beltsville, MD: National Agricultural Library.

Hoban, T.J. IV. 1992. Teamwork for conservation education. Journal of Soil and Water Conservation 47(3):231-233.

Israel, G.D., and K.M. Wilson. 2006. Sources and channels of information used by educational program clients. Journal of Applied Communications 90(4):55-78.

Johnson, T.J., and B.K. Kaye. 2004. Wag the blog: How reliance on traditional media and the Internet influence credibility perceptions of Weblogs among blog users. Journalism and Mas Communication Quarterly 81(3):622-642.

King, D. 2003. Communicators as architects of change. Journal of Applied Communications 87(1).
Lamberti, A. 2007. Talking the Talk: Revolution in Agricultural Communication. New York, NY: Nova Science Publishers.

Mocigemba, D. 2008. P4P_podcasting for participation: How can digital grassroots media support sustainable development? International Journal of Sustainability Communication CCP2.

Paskoff, B.M. 1990. History and characteristics of agricultural libraries and information in the United States. Library Trends 38(3):331-349.

Rogers, E.M. 2003. Diffusion of Innovations, 5th ed. New York, NY: Free Press.

Rogers,E.M.,and D.L.Kincaid.1981.Communication Networks: Toward a New Paradigm for Research. New York, NH: Free Press.

Tarrant, M.A., C. Overdevest, A.D. Bright, H.K. Cordell, and D.B.K. English. 1997. The effect of persuasive communication strategies on rural resident attitudes toward ecosystem management. Society and Natural Resources 10(6):537-550.

Vogele, C., and M. Garlick. 2006. Podcasting Legal Guide: Rules for the Revolution. Cambridge, MA: Clinical Program in Cyberlaw, Berkman Center, Harvard Law School.

Xie, K., and M. Gu. 2007. Advancing cooperative extension with podcast technology. Journal of Extension 45(5):5TOT2. 